\title{
LEARNING TRENDS, STRATEGIES AND CONSIDERATIONS: AN EVALUATION OF THE HYPRID E-LEARNING PRACTICE AT THE REGIONAL IT INSTITUTE USING DEMAND-DRIVEN LEARNING MODEL
}

\author{
Nada Megahed \\ Academic Programs Manager for Curriculum and Learning Quality \\ Sara Yakout \\ MSc Program Manager \\ Tamer Darwish \\ Marketing Manager
}

Khaled Wahba

Academic Advisor

\begin{abstract}
As a force contributing to social and economic development, E-Learning is fast becoming an accepted and indispensable part of the main-stream of educational systems in both developed and developing countries, with particular emphasis for the latter. This growth has been stimulated in part with the increasing use of networked computers as a medium for network-enabled transfer of skills, information, and knowledge in various areas. The traditional context of learning is experiencing a radical change. The concept of traditional education does not fit well with the new world of lifelong learning, in which the roles of instructor, students, and curriculum are changing. Rather than replacing traditional classrooms and teaching methodology, E-Learning should serve as a complementary mechanism to lifelong or remote learning.
\end{abstract}

Today, Egypt has thousands of training companies and institutions giving training and educational programs, including degree, non-degree and certificate programs. The need to evaluate an E-learning system has been proved to be vital to establishments in the planning phase of their training programs. The choice is critical and quality management becomes crucial. One of the biggest E-learning projects in Egypt is the E-learning system of the ministry of education. This system is based on a well known collaboration suite named Centra. On the other hand, E-learning in the Egyptian universities/institutions is still in the very early stage. There are many theoretical and technological issues that need to be explored. Therefore, the need for a tested quality management scheme is becoming crucial.

E-learning quality has been defined in terms of the design of the e-learning experience, the contextualized experience of learners, and evidence of learning outcomes. However, E-Learning course design and overall program quality are sometimes compromised in an effort to simply get something running in response to pressing demands of the consumer. Accordingly, educators and researchers have voiced concerns over the lack of appropriately rigorous evaluation studies of E-Learning programs and systems. Hence, comes the Demand-Driven Learning Model (DDLM) as a Quality Standard. The DDLM has five main components: the quality standard of "superior structure," three consumer demands (content, delivery, and service) and learner outcomes. It is important that these constructs are operationally defined to allow easy application of the DDLM by practitioners and researchers.

On the other hand, Literatures have shown different best practices in the area of assessing and evaluating E-Learning quality in different contexts and in different countries. However, best practices in Egyptian context are still very limited and not mature enough to be reported. Accordingly, the objective of this paper is to demonstrate the best practice of the Hybrid E-Learning model at the Regional IT Institute, as well as to evaluate 
this Hybrid model using the Demand-Driven Learning Model. It emphasizes the two E-Learning degree programs delivered by the Institute namely: the Master of Science in Business Information Technology, delivered in cooperation with Middlesex University in the UK, and the Master of Science in Human Resources Education in cooperation with University of Louisville in the USA.

Building on the DDML model, the evaluation has been performed through conducting four focus groups, in which current and previous students have participated. The results showed that participants emphasized the critical importance of the blend between the two learning extremes (the traditional and the E-Learning models) particularly in the dimensions of the delivery, service and outcomes. Meanwhile, the content dimension showed no significant difference among the three models, namely; the E-learning, the traditional learning and the hybrid E-Learning model applied at RITI. The concept of Hybrid E-Learning is still not mature enough; however, presenting the best practice of the Regional IT Institute may help adding to the stream of literature in this domain, particularly in the Middle East area.

\section{OVERVIEW}

Major changes have occurred in the world economy, in particular with regard to the informationbearing technologies. These demand the attention of governments for education and for human resource development (UNESCO, 2002). While the last two decades have seen considerable growth in education and training, many countries are struggling with limited access to education and training for young people, and at the same time have to address the basic needs of an older generation. Low quality and insufficient relevance are other concerns. At the root is often the problem of financing adequate provision, and of outdated structures for education and training.

As a force contributing to social and economic development, E-Learning is fast becoming an accepted and indispensable part of the main-stream of educational systems in both developed and developing countries, with particular emphasis for the latter (UNESCO, 2002). This growth has been stimulated in part with the increasing use of networked computers as a medium for network-enabled transfer of skills, information, and knowledge in various areas (Carswell, 1997). Also by the recognition that traditional ways of organizing education need to be reinforced by innovative methods, if the fundamental right of all people to learning is to be realized (UNESCO, 2002).

The traditional context of learning is experiencing a radical change. The rapid development of information and communication technologies (ICTs) and the move towards more knowledge-intensive, interdependent and internationalized societies create new challenges and opportunities for the design and delivery of education (UNESCO, 2002). The concept of traditional education does not fit well with the new world of lifelong learning, in which the roles of instructor, students, and curriculum are changing. Teaching and learning are no longer restricted within traditional classrooms (McAllister and McAllister, 1996; Marold et al, 2000). Rather than replacing traditional classroom teaching methodology, E-Learning serves as a complementary mechanism to lifelong or remote learning. Learning methods need to become more portable and flexible. E-Learning has been crucial to meet this new challenge.

\section{LITERATURE REVIEW}

\subsection{E-Learning versus Distance Education: Concept and Contributions}

Generally, E-Learning refers to any type of learning situation when instructional content is delivered electronically via the Internet when and where people need it. It is an inescapable element of business in the new economy. As a promising solution, E-Learning technology has been widely adopted by many companies to expand their training market to previously out-of-reach employees. It eliminates the barriers of time and geographical distance, so continuing staff development can accommodate diverse learning environments such as homes, offices, and offsite conference rooms. It also offers learning-on-demand opportunities to individual employees while reducing training time and cost.

E-learning systems can usually be described as made up of a range of components such as: the mission or goal of a particular system, programmes and curricula, teaching/learning strategies and techniques, learning 
The market for Web-based corporate learning in US was expected to reach $\$ 11.4$ billion in 2004, up from \$550 million in 1998 (Kerrey and Isakson, 2000). In academics, E-Learning has supported significant improvement in interactivity, collaboration, and delivery of online education. The educational opportunities have been carried to many remote corners of the earth via the Internet. The new focus of distance learning is to build a cost-effective learning infrastructure that enables anytime, anywhere, self-paced, and interactive learning.

For the student/learner open and distance learning means increased access and flexibility as well as the combination of work and education. It may also mean a more learner-centered approach, enrichment, higher quality and new ways of interaction (UNESCO, 2002). For employers it offers high quality and usually cost-effective professional development in the workplace. It allows upgrading of skills, increased productivity and development of a new learning culture.

For governments the main potential is to increase the capacity and cost-effectiveness of education and training systems, to reach target groups with limited access to conventional education and training, to support and enhance the quality and relevance of existing educational structures, to ensure the connection of educational institutions and curricula to the emerging networks and information resources, and to promote innovation and opportunities for lifelong learning. Traditionally, governments have introduced distance education provision in order to (UNESCO, 2002):

- Increase access to learning and training opportunity;

- Provide increased opportunities for updating, retraining and personal enrichment;

- Improve cost-effectiveness of educational resources;

- Support the quality and variety of existing educational structures;

- Enhance and consolidate capacity.

It is more than ever clear that open and distance learning will be an important element of future education and training systems. It is approaching acceptance within mainstream education and training in such a way that it will make up part of the repertoire of most educational institutions in the future. The emergence of new forms of distance learning based on new information and communication technologies; in particular those supported by the Internet and using the World Wide Web, have significant pedagogical, economic and organizational implications. Governmental leadership concerning network development and access will be essential in this sphere.

\subsection{Components of Distance Learning Systems}

Open Education, E-Learning, Distance Education are all labels that UNSECO attempted to differentiate among them in order not to misunderstand each one of them. So, according to (UNESCO, 2002), Open and Distance Learning are usually contrasted with conventional or face-to-face education, which may be described as the form of education, which takes place in a classroom or an auditorium. However, both distance and face-to-face education are labels covering a wide range of variations and methods. Face-to-face education may vary along a continuum from one-to-one tutorials, group activities, seminars and classroom teaching to lectures for large audiences. In each case different educational philosophies may be applied and different methods may be used. Face-to-face education may be supported by a range of media, and may be combined with periods of independent study. In a similar way, distance education has a variety of forms, according to the underlying educational philosophy, organizational approach and choice of technology, and distance educators may incorporate into their programmes an element of face-to-face teaching.

Four main generations have determined the Historical Evolution of Distance Education, each with its own organizational form derived from the main form of communication.

$1^{\text {st }}$ Generation: Correspondence Systems originated at the end of the nineteenth century, and are still the most widely used form of distance education in less developed countries. Based around a study guide in printed text and often 
accompanied by audio and video components such as records and slides, interaction in the correspondence method is by letters and other written or printed documents sent through postal systems.

$2^{\text {nd }}$ Generation: Educational Television and Radio Systems use various delivery technologies' terrestrial, satellite, and cable television and radio to deliver live or recorded lectures to both individual home-based learners and groups of learners in remote classrooms where some face-to-face support might be provided. Some systems offered limited audio or video-conferencing links back to the lecturer or a moderator at a central point.

$3^{\text {rd }}$ Generation: Multimedia Systems encompass text, audio, video, and computer-based materials, and usually some face-to-face learner support delivered to both individuals and groups. In this approach, which is that used by the open universities, instruction is no longer an individual's work, but the work of teams of specialists, media specialists, information specialists, instructional design specialists, and learning specialists. Programmes are prepared for distribution over large numbers of learners, usually located across a whole country.

$4^{\text {th }}$ Generation: Internet-Based Systems in which multimedia (text, audio, video and computer-based) materials in electronic format are delivered to individuals through computers, along with access to databases and electronic libraries, and which enable teacher-student and student-student, one-to-one, one-to-many, and many-to-many interactions, synchronously or asynchronously, through e-mail, computer conferences, bulletin boards, etc.

Moreover some other models as derivatives from the $4^{\text {th }}$ Generation have been evolved:

Single Mode Institutions are those in which distance education is the sole mission, to which teachers and administrative staff are exclusively dedicated. Course development, instruction, evaluation and other educational processes are tailored to the distant learner.

Dual Mode Institutions there may be an administrative staff whose sole responsibilities are distance education, but usually it is the teachers of the parent body who provide the teaching. There is some allowance for distance teaching methods in course design, instruction and evaluation and teachers may have some special training. The most common distance learning design process is the author-editor model; each course is based on a study guide prepared by a single course writer. Where the Internet is available the study guide may be accessed online rather than in hard copy. This model is in many literatures called the Hybrid or the blended model. In this current study, the Dual Mode Institutions will be the focus.

\section{Components of all Distance Learning Systems}

It is very important in this section to explore the main components of Distance Education from the side of several views e.g. in the report (UNESCO, 2002) in order to build the benchmark for the current case study (Regional IT Institute) in this research.

It is the mission of a distance learning system that defines its role within the context of national policy. The mission may be directed towards particular purposes, target groups, regions, sectors or levels of education and training, and driven by particular values and philosophies of learning and education. The mission statement of a public institution will be part of a national policy, while the mission of private organizations may fulfill subsidiary functions in relation to the public institutions. On the other hand, private organizations must respond to the needs of particular market segments, especially of the labor market, both quickly and efficiently, (UNESCO, 2002). In all cases studies showed that for efficient distance education system, certain group of pillars or components are very crucial, namely; (1) Courses and Curricula, (2) Teaching Strategies and Techniques, (3) Learning Materials and Resources, (4) Communication, (5) Support Delivered Locally, (6) Student and Staff Management, (7) Management and Administration, (8) Housing and Equipment, and (9) Evaluation.

(1) Courses and Curricula define the profile of a system or institution. They should be related to the mission and to the defined needs or markets. Many distance education systems provide courses in preparation for examinations and degrees, which are equivalent or similar to those offered by conventional institutions, and subject to similar regulations as regards content, admission and assessment.

(2) Teaching Strategies and Techniques depend partly on the type of programme and the needs they are designed to meet, but they also depend on the educational philosophy and values of the particular system, and the educational 

economy and the choice of technology.

(3) Learning Materials and Resources are essential components in all distance learning systems. Comprehensive, welldesigned materials may stimulate self-directed learning and thus influence the quality of the system as a whole. Design, development and production of materials are often considered as a sub-system in distance teaching organizations. Previously produced, existing materials, text-books, software etc. may be used but in most cases each programme benefits from having specifically designed learning materials.

(4) Communication between teachers and learners is a necessary component in distance education, as in all other forms of education. Communication technologies distribute messages in text, still and moving images, and sound. Knowledge-generating messages may be communicated to large numbers of learners, either synchronously or asynchronously, pushed by broadcasting or accessed on demand through audio/video players or Internet. As these devices change, so the quality and nature of the messages will change.

Communication serves two purposes. One is the distribution of information. This delivery system may comprise both distribution of pre-packaged material and transmission of synchronous or broadcast programmes, lectures etc. The second role of communication is the crucial component of all education which is the Interaction between Teachers and Learners, and, where possible, between Learners also. In some forms of distance education this learnerlearner interaction is practically non-existent, but in most cases it is considered important and may be provided in different ways. Often students meet together physically in groups, some times connected with other forms of local support. New technologies allow the organization of virtual groups., and in countries where access to the Internet is common, this is the fastest growing approach to distance teaching.

(5) Support Delivered Locally is a common component in most Single Mode Institutions. A letter, a telephone call or an e-mail message is of course delivered locally and is more likely to be the means of learner support in Dual Mode Institutions. What is meant here is, however, support in a form that allows some kind of direct (face-to-face) interaction between the learner and a teacher or a mentor/facilitator. This component may be organized completely as face-to-face events, or in combination with communication at a distance (teleconferences etc.). Local support is usually given in a study centre or resource centre. The centre may also offer access to other learning resources, equipment etc.

(6) Student and Staff Management subsystem is often distinguished from the course materials sub-system. From an administrative perspective the student and staff management sub-system comprises admission, allocation to courses and student services, administering the learning and teaching procedures, assignments and assessment, monitoring drop-out and completion, and examinations. Staff may be contracted on a part-time basis or may be in the core faculty in the case of a dual mode institution, but in either case they have to be recruited, trained and monitored. A range of other experts with different qualifications is also needed, either as full-time staff or as external consultants: planners, instructional designers, developers and producers, researchers, media experts, marketing experts and administrative staff.

Effective (7) Management and Administration needs not only competent staff, but also well designed, efficient administrative systems and routines, planning and monitoring systems, budgetary and accounting systems etc. Many of these will be quite different from the corresponding systems needed in the management of other forms of education.

The requirements of (8) Housing and Equipment may also be very different from conventional education institutions. A single mode distance learning system has no residential students, and thus there is little need for classrooms, lecture theatres etc. at the central location. Such facilities may be needed locally, and are often provided in co-operation with local institutions. At the central location there will be need for production facilities and storage capacity, although some decentralized production is also possible. In a dual mode institution these distance education facilities have to be accommodated alongside the space dedicated to the Institution's primary mission. 
Finally, (9) Evaluation should be a component, in order to provide information relevant to the adjustment of the roles and operation of system components, and in order to secure their optimal contribution and development. The success of any distance education institution, dual or single mode, is highly dependent on the efficiency and effectiveness of the monitoring and evaluation system, without which it may be impossible for administrators to be aware of problems in the system until the system itself breaks down. It is not possible to rely upon the kind of informal, unstructured feedback that may be sufficient in the conventional classroom.

\subsection{Distance Education in Higher Education}

There are more distance learning courses offered at the tertiary level than at any other. This has been the case since the invention of the distance education method near the end of the nineteenth century when the use of new technology (i.e. national rail systems that supported national postal systems) made it possible to deliver higher education beyond the boundaries of the campus, especially in the United States, Canada, Australia, South Africa, and Russia. In turn these countries led the way in the use of radio for university level teaching, then television, and today the Internet. In these nations the preferred organizational form was, and remains, the dual mode university.

The development of the Open University in the United Kingdom provided the model for the integrated multimedia systems approach to the delivery of higher education by a single mode university, a model that has been emulated in more than a score of other countries. Open universities have their own degrees and curricula, though these are usually similar to the curricula and degrees of a conventional university. The similarity of curricula and degree structures may be seen as a demonstration of equal quality, and makes the recognition of distance education at the tertiary level easier. Many of the open universities have developed into mega-universities with more than 100,000 students.

The Internet has attracted the attention of university academics to the idea of distance teaching in a way that no previous technology managed to do. Together with the pressure from new competitors for student

enrollment, this enthusiasm for technology explains the growing number of traditional universities that are converting to dual mode status. Such universities usually teach the same curricula for distance students as for their residential students and subject the students (but not always) to the same entrance requirements and examinations.

The success and expansion of single mode open universities on the one hand, and the transformation of traditional universities to dual mode universities on the other, are important contributions to the diversification and development of higher education systems.

\subsection{Distance Education in Arab States}

Open and distance education in the Arab states is generally more recent and less extensive than in some other regions of the world, (UNESCO, 2002). There is, however, growing interest in the potential of distance education to solve some of the educational challenges facing the region. Distance education has great potential to meet mass demand for education, but although Egypt reports using communication technologies in school and both radio and video-conferencing for teacher education, the level of usage of distance education is lower than in other E-9 countries. In Algeria, the Centre National d'Enseignement Generalisé offers general and technical education to Baccalaureate level, education in preparation for certificates and diplomas of different levels, and specialist professional training. Courses are offered through print, newspapers, audio- and videocassettes, radio, telephone and group study. Some 100,000 students are enrolled.

The Sudan Open Learning Organization (SOLO) has operated since 1984 to provide a number of educational programmes including basic education to adult refugees in Ethiopia, Somalia and Sudan. At the basic level it offers a literacy programme, a primary health care programme, income generating and small business skills for women, and a teacher assistance course aimed at training basic level teachers employed within the refugee schools, (UNESCO, 2002).

At the higher education level, the Palestinian Al-Quds Open University began teaching in 1991, using an integrated multimedia approach. Set up to meet the needs of Palestinian students in Gaza and the West Bank, the University initially operating out of Amman, moved its headquarters to Jerusalem in 1993. More recently, the Arab Open University project has been formally established with its headquarters in Kuwait. Plans are afoot to 
launch programmes in a number of Arab countries (Bahrain, Egypt, Jordan, Kuwait, Lebanon and Saudi Arabia), with others to follow. Meanwhile, the level of frustrated demand for entry to higher education has attracted foreign providers to the region: a recent study indicated that in Bahrain, for example, no fewer than 36 foreign providers were offering distance education programmes.

\subsection{Present Trends in OPen ANd Distance LeARning: Creating a New Educational Platform}

One of the first areas that requires change is higher education's perception of technology as it relates to its mission. For the past decade, most attempts to use technology in higher education have been very haphazard: systems have been designed only to automate existing processes, computers have been thought of as strictly computational devices, and desktop workstations have not accomplished much more than replacing the typewriter and the adding machine.

Today, however, technology is creating a new educational platform and is reconfiguring the way a student learns. Networked learning, accessing, libraries, scholars, networks, and information worldwide are evolving. Through technology a student's educational experience can be immeasurably richer. Various typologies of Internet Applications in Education (IAE) have been proposed in the literature in recent years. Two main approaches to the segmentation of this project-domain have been revealed through the analysis of recent experience. The technology-oriented approach is the most widespread.

For example, statistical research on the use of the electronic communication in open and distance learning, conducted by UNESCO in 1995 (Euler and Berg, 1998), has identified the following types of applied telecommunication media in educational programmes: telephone; fax; audio-conference; video-conference; electronic mail; access to databases.

Ellsworth (1994) proposes the classification of Internet tools in accordance with the types of interaction between the participants in the educational process as follows: interaction between the students and professors

in the educational process; interaction between the students and professors while searching for information on the Net; joint activities of professors and the administration; students' joint research projects.

A.

\section{B. 2.6 Differences between Traditional Learning Processes and E-Learning}

Traditional learning processes can be characterized by: (1) Centralized authority (content is selected by the educator), (2) Strong push delivery (instructors push knowledge to students), (3) Lack of a personalization (content must satisfy the needs of many), and (4) The linear/static learning process (unchanged content).

However, such an organization of the learning process results in an expensive, slow and too unfocused (problem-independent) learning process. Dynamically changing business environments put completely different challenges on the learning process - it has to be efficient, just-in-time and task relevant (problem-dependent). This can be solved with E-Learning, i.e. with a distributed, student-oriented, personalized, and nonlinear/dynamic learning process.

Table 1: Differences between training and E-Learning (Drucker 2000)

\begin{tabular}{|c|c|c|}
\hline Dimensions & Training & E-Learning \\
\hline Delivery & Push - Instructor determines agenda & Pull - Student determines agenda \\
\hline Responsiveness & $\begin{array}{l}\text { Anticipatory - Assumes to know the } \\
\text { problem }\end{array}$ & $\begin{array}{l}\text { Reactionary- Responds to problem at } \\
\text { hand }\end{array}$ \\
\hline Access & $\begin{array}{l}\text { Linear - Has defined progression of } \\
\text { knowledge }\end{array}$ & $\begin{array}{l}\text { Non-linear - Allows direct access to } \\
\text { knowledge in } \\
\text { whatever sequence makes sense to the } \\
\text { situation at hand }\end{array}$ \\
\hline Symmetry & $\begin{array}{l}\text { Asymmetric - Training occurs as a } \\
\text { separate activity }\end{array}$ & $\begin{array}{l}\text { Symmetric - Learning occurs as an } \\
\text { integrated activity }\end{array}$ \\
\hline
\end{tabular}




\begin{tabular}{|c|c|c|}
\hline Dimensions & Training & E-Learning \\
\hline Modality & $\begin{array}{l}\text { Discrete - Training takes place in } \\
\text { dedicated } \\
\text { chunks with defined starts and stops }\end{array}$ & $\begin{array}{l}\text { Continuous - Learning runs in the } \\
\text { parallel to business } \\
\text { tasks and never stops }\end{array}$ \\
\hline Authority & $\begin{array}{l}\text { Centralized - Content is selected from } \\
\text { a } \\
\text { library of materials developed by the } \\
\text { educator }\end{array}$ & $\begin{array}{l}\text { Distributed - Content comes from the } \\
\text { interaction of the } \\
\text { participants and the educators }\end{array}$ \\
\hline Personalization & $\begin{array}{l}\text { Mass produced - Content must satisfy } \\
\text { the } \\
\text { needs of many }\end{array}$ & $\begin{array}{l}\text { Personalized - Content is determined } \\
\text { by the individual } \\
\text { user's needs and aims to satisfy the } \\
\text { needs of every user }\end{array}$ \\
\hline Adaptivity & $\begin{array}{l}\text { Static }- \text { Content and } \\
\text { organization/taxonomy } \\
\text { remains in their originally authored } \\
\text { form } \\
\text { without regard to environmental } \\
\text { changes }\end{array}$ & $\begin{array}{l}\text { Dynamic }- \text { Content changes } \\
\text { constantly through user input, } \\
\text { experiences, new practices, business } \\
\text { rules and heuristics }\end{array}$ \\
\hline $\begin{array}{l}\text { Nonverbal Communication } \\
\text { (body language, facial expressions and } \\
\text { changing voice tones which form tools } \\
\text { that we use too communicate meaning } \\
\text { to others.) }\end{array}$ & $\begin{array}{l}\text { Is present and mot tutors depend } \\
\text { heavily on nonverbal communication. }\end{array}$ & Strongly diminished \\
\hline physical connections & $\begin{array}{l}\text { Is present and allows both students } \\
\text { and tutors to best express themselves } \\
\text { and communicate together. }\end{array}$ & $\begin{array}{l}\text { There is a lack of physical connections } \\
\text { doesn't allow usual demonstrations by } \\
\text { instructors and prompt face to face } \\
\text { feedback from instructors. }\end{array}$ \\
\hline
\end{tabular}

\subsection{Potential Benefits versus Potential Negatives of E-Learning}

E-learning has definite benefits over traditional classroom training. While the most obvious are the flexibility and the cost savings from not having to travel or spend excess time away from work, there are also others that might not be so obvious. Some of these benefits are:

\section{- Anytime, Anywhere}

E-Learners have access at anytime and anywhere to learning (not entirely true). E-Learners can go through training sessions from anywhere, usually at anytime. This Just-In-Time (JIT) benefit can make learning possible for people who never would have been able to work it into their schedules prior to the development of e-learning.

- Cost Reductions

For asynchronous training programs, e-training is virtually free once one reaches the breakeven point. Synchronous programs will have continued costs associated with the instructor managing the class, but will still be lower than traditional courses. In other words E-Learning involves Low delivery cost: fewer instructors, less traveling, less classroom, less... (But higher initial setup cost).

- $\quad$ Fast Content updates on Internet

It can be updated easily and quickly - Online e-learning sessions are especially easy to keep upto-date because the updated materials are simply uploaded to a server. CD-ROM-based programs may be slightly more expensive to update and distribute, but still come out cheaper than reprinting manuals and retraining instructors.

\section{- It provides a Consistent Message}


E-learning eliminates the problems associated with different instructors teaching slightly different material on the same subject. For company-based training, this is often critical.

- It moves Faster

According to an article by Jennifer Salopek in "Training and Development Magazine," ELearning courses progress up to 50 percent faster than traditional courses. This is partly because the individualized approach allows learners to skip material they already know and understand and move onto the issues they need training on.

- Flexibility:

It is acts as Round-the-clock learning. In other words, it is self-paced - Most e-learning programs can be taken when needed allowing the learner to go through smaller chunks of training that can be used and absorbed for a while before moving on.

- It can lead to increased retention and a stronger grasp on the subject

$-$

This is because of the many elements that are combined in e-learning to reinforce the message, such as video, audio, quizzes, interaction, etc. There is also the ability to revisit or replay sections of the training that might not have been clear the first time around. Try that in a crowded auditorium!

- Access to Material 24/7 if desired

Allowing student to fit learning around their schedule

- Scalability

Reaching larger markets and allowing large number of users

- Community building:

Virtual learning community

- More effective learning.

- Personalized instruction.

Negatives can be summarized as:

- The Loneliness of the E-Learner (Social disconnection).

- Nobody is there to motivate the E-Learner. The E-Learner should be self motivated.

- The basic IT skills required by E-Learning, may act as an obstacle for many students.

- Authentic assessment, teaching skills (compared to theory) online, not as effective as classrooms

\section{INTERNET USAGE AND WEB-BASEd EdUCATION IN EgYPT: THE CASE STUDY \\ 3.1 Objective of the Study}

Literatures have shown different models and practices in the area of E-Learning and Distance Education in different contexts and countries. However, best practices in Egyptian context still are very limited and not mature enough to be reported and to learn from.

In that respect, the objective of this work is to demonstrate the best practice of the hybrid E-Learning (Distance Education) model at the Regional IT Institute in form of evaluation based on the demand-driven learning model and on the light of UNSECO report in 2002.

\subsection{Problem Statement}


Today, Egypt has thousands of training companies and institutions giving training and educational programs, including degree and certificate programs. The need to evaluate the E-learning and Distance Education systems has been proved to be vital to establishments in the planning phase of their training programs. The choice is critical and quality management becomes crucial. One of the biggest E-learning projects in Egypt is the E-learning system of the ministry of education. This system is based on a well-known collaboration suite named Centra. On the other hand, E-learning in the Egyptian universities is still in the very early stage. There are many theoretical and technological issues that need to be explored. Therefore, the need for a tested quality management scheme is becoming crucial.

\section{Conceptual Model of the Study}

\subsection{Quality is the Word}

E-learning quality has been defined in terms of the design of the e-learning experience, the contextualized experience of learners, and evidence of learning outcomes (Carr \& Carr, 2000). However, ELearning course design and overall program quality are sometimes compromised in an effort to simply get something up and running in response to pressing demands of the consumer. Accordingly, educators and researchers have voiced concerns over the lack of appropriately rigorous evaluation studies of E-Learning programs and systems. Hence, comes the Demand-Driven Learning Model DDLM as a Quality Standard.

The DDLM was developed through a collaborative process between industry experts and academics, the latter having strong foundations in curriculum design, evaluation methods, and psycho pedagogy. After an exhaustive review of the literature on constructs related to e-learning, members of research teams constructed a conceptual framework to address high quality standards within e-learning. The demand-driven learning model was developed in Canada. The technology is seen as support or a tool to achieve the desired learning outcomes in a cost-effective way. The primary purpose of the model is to encourage academics to take a proactive role in the development and use of technology in the teaching process. This model has proposed a high-quality

standard of "superior structure," grounded in consumer (learner) demands and recognizes the needs of instructors and designers (MacDonald et al, 2002).

It emphasizes the three consumer demands: high quality content, delivery and service. Content should be comprehensive, authentic and researched. Delivery is web-based and the interface of the used E-Learning programs should be user-friendly with communication tools to support interactivity. Service should include the provision of resources needed for learning as well as any administrative and technical support.

In addition to the quality issues, E-Learning involves high levels of investment that need to be justified. Evaluation has, therefore, become important across the sector as a means to demonstrate effectiveness and costeffectiveness of learning technologies. However, there has been a gradual shift in the use of evaluation for developmental rather than judgmental purposes. Evaluation is best seen not only as a necessary adjunct to accountability, but also as an integral part of good professional practice -contextualization rather than standardization. Evaluation can provide a vehicle for reflective practice: thinking critically about curriculum development and encouraging continuous improvement of one's own teaching performance. Some academic staff has used evaluation of innovative approaches as evidence for recognizing teaching achievements in the promotion process (MacDonald et al 2002).

E-learning, by its nature, is innovative: it introduces new modes of teaching, learning and assessment. In introducing E-learning, one will be reflecting on whether "what he is doing and how he is doing it" is meeting his intended aims and objectives. A well-designed DDLM evaluation survey should provide evidence as to the reasons why, and extent to which, a particular approach has been successful and of potential value to others. Baume, D. (2004) distinguishes between "succeeding" to mean achieving goals and "going well" to mean adopting satisfactory or excellent processes. He argues that good process does not always correlate with attainment of goals, and vice versa.

\subsection{Factors and Variables Involved in the Model}

MacDonald et al (2001) proposed that the DDLM has five main components: the quality standard of "Superior Structure", three consumer demands (Content, Delivery, and Service) and Learner Outcomes. It is important that these constructs are operationally defined to allow easy application of the DDLM by practitioners 
and researchers. Quality assurance in the DDLM is implied through ongoing program evaluation and continual adaptation and improvement and this comply with the study conducted by the UNESCO, 2002. A natural consequence of the development of DDLM constructs would be a pilot test of utility in applied settings. Figure 1 represents a graphical representation of DDLM construction. Next section will summarize the factors and variables in the model.

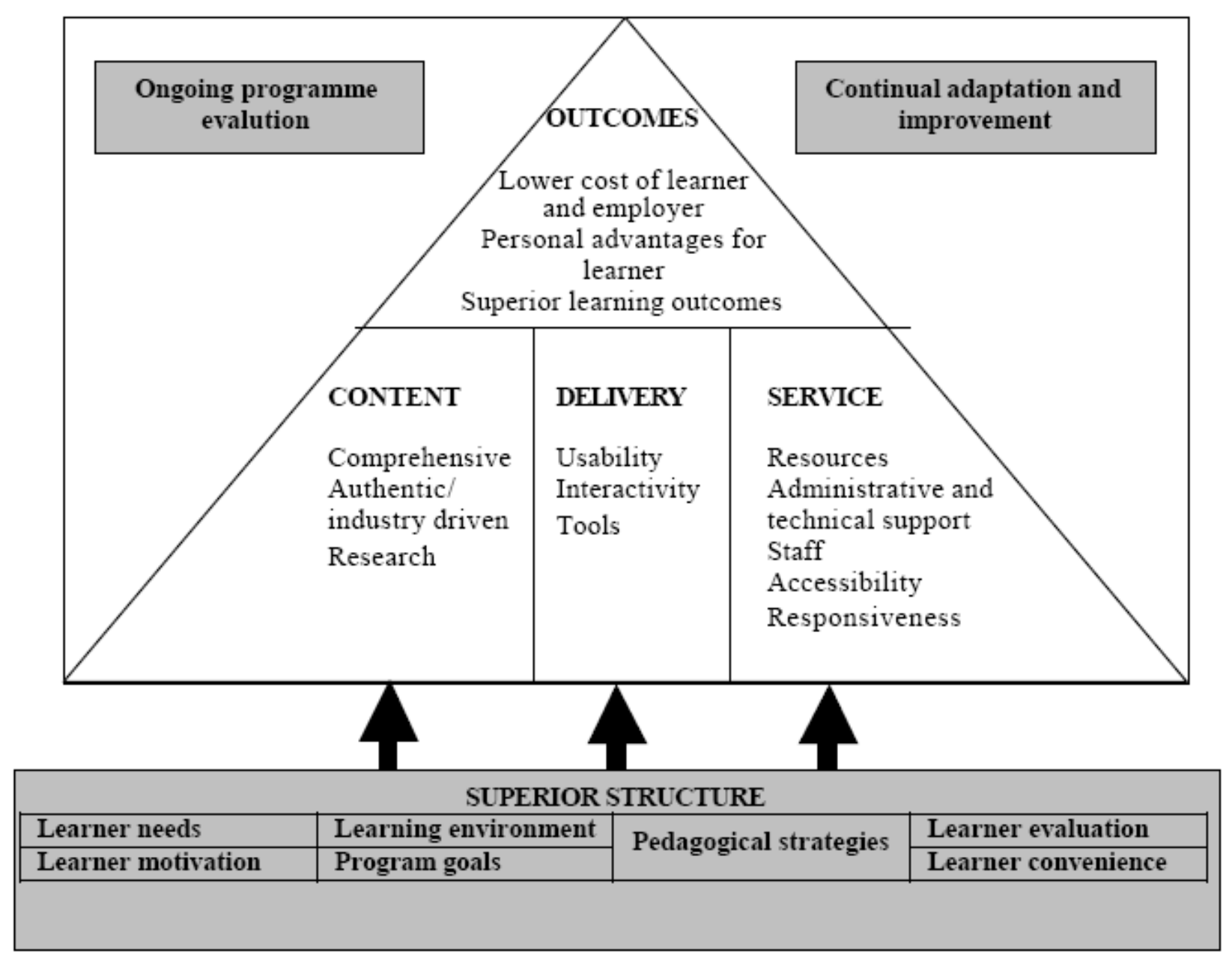

Source: MacDonald et al (2001)

Figure 1: Graphical representation of DDLM construction

\subsubsection{Consumer Demand: Content}

In the DDLM framework, high-quality content is considered to be comprehensive, authentic/industrydriven, and researched.

- Comprehensive - Course content covers all the information that consumers need to know. Such information is presented objectively and through unbiased language. Content matches the consumer's level of understanding, and it covers topics in appropriate breadth and depth.

- Authentic/industry-driven - Course content faithfully reflects problems and issues that arise in the workplace. Learners engage in activities that present the same type of cognitive challenges they encounter in the work environment. This enables the acquisition of information, concepts, and skills that are meaningful and relevant to the present or future workplace. Authentic, industry-driven content is ensured by obtaining direct input from industry professionals, with regard to the current or future educational needs of employees and employers. 
- Researched-Course content is grounded in accessible and validated, empirical research. Input from content experts in both academia and industry is solicited to ensure that high quality prevails.

\subsubsection{Consumer Demand: Delivery}

The DDLM assumes that learning programs are interactive and Web based. In this context, high-quality delivery is defined as delivery that carefully considers usability, interactivity, and tools.

- Usability - The user interface of DDLM-based programs is carefully designed and tested to ensure usability. For example, Web pages have strong navigational support and standard Web conventions are adhered to. Information on the site is kept up-to-date, with no dead ends or stale links. Web page length is appropriate for DDLM consumers and new Web technology is used only if it supports consumer needs. DDLM-based learning systems also break instruction into clear sections such as: opening, information presentation, exercises, interaction, and closing. This gives learners a sense of pacing and completion. The time required to complete each section is tracked and adjusted as needed.

- Interactivity - A critical aspect of delivery is the interaction of the learner with other learners, with facilitators/professors, and with content. DDLM-based programs are designed to ensure the incorporation of activities encouraging interactivity.

- Tools — The DDLM identifies technologies as intellectual tool kits that help learners build more meaningful interpretations and representations of the world. The chosen tools for DDLM-based programs support instructional objectives, with careful consideration of the advantages and limitations of each tool. This interpretation is consistent with the principle of technological minimalism, defined as "the unapologetic use of minimum levels of technology, carefully chosen with precise attention to their advantages and limitations, in support of welldefined instructional objectives".

Presenting material in only one format can limit what and how learners come to understand issues. Therefore, a variety of media and communication tools are used to accommodate different learning styles. With a combination of text, graphics, video, and audio, DDLM-based programs cater to various learning styles and improve the total learning experience.

The type and degree of interaction desired directly drives tool selection. DDLM-based programs incorporate tools that enable both content interactions and social interactions. Content interactions are situations in which the learner interacts with the content of the course, experiences it, process it, and reflect on it; social interactions refer to social interactions with other learners and the facilitator/instructor about content. Tools for content interaction include video and audio clips, lectures through video conferencing, text documents, and journal presentations. Tools associated with social impact include video conferencing, discussion groups, chat rooms, and e-mail.

\subsubsection{Consumer Demand: Service}

The DDLM defines high-quality service as service that provides the resources needed for learning as well as any administrative and technical support needed. Such service is supported by skilled and enthusiastic staff who are accessible and responsive.

- Resources - In DDLM-based systems, resources help learners determine what their learning needs are and how those needs could best be met. These elements reflect the complexity of the environment and include authentic activities. Learning resources are presented in a number of forms to allow learners to examine concepts from multiple perspectives. Resources also encourage learners to be reflective and aware of their own thinking and learning processes; such reflection, combined with how learners comes to view and incorporate new information into the context of their lives, promotes development. Finally, resources are chosen to encourage social negotiation, which allows insights and the elaboration of concepts and ideas to occur.

- Administrative and Technical Support-In DDLM-based systems, administrative and technical support is freely available. Learners receive a thorough introduction to the learning environment when they enter it. Support is provided to help learners use and access the systems supporting the learning environment. Moreover, learning 
facilitators and professors also have access to technical support, and these support personnel are selected for their experience and formal credentials.

- Staff-In DDLM-based systems, the learning facilitators/professors and technical support persons are qualified and experienced individuals. The learning facilitators/ professors create a positive learning experience for each learner and are enthusiastic to individual learner needs. Individuals responsible for the design, development, and delivery of the learning environment work as an effective team. Staff members

demonstrate effective collaboration, respect for roles, and effective communication; they also share their expertise and have shared values.

- Accessibility_-Access to services and staff is straightforward. Learning facilitators/ professors and technical support persons are available and easy to reach. Unconstrained access to services such as libraries, bookstores, and an extensive range of other learning resources is provided via Web links.

- Responsiveness_-All requests for service and help are met with a minimum amount of waiting. This can be achieved by providing prompt feedback on assignments, fast responses to e-mails, and timely assistance.

\subsubsection{Superior Structure as the Quality Standard}

Superior structure is proposed as the high-quality standard for E-learning system. Consumers in all learning programs demand high-quality content, high-quality delivery, and high-quality service. When superior structure is present, the E-learning system has met the DDLM defined standard for consumer demands. Superior structure may be understood as the required foundation that makes it possible to provide this level of content, delivery and service.

In the DDLM, superior structure is achieved by anticipating the needs of the learners and considering what motivates learners. This will require a collaborative and healthy learning environment that has convenient access and where curriculum is designed according to program goals. Pedagogical strategies are implemented that are appropriate for online learning. The quality of E-learning is monitored via a system of regular evaluation of learners. The following considerations define superior structure:

- Anticipate the Needs of the Learner-As part of meeting learners' demands for content delivery, and service, DDLMbased programs meet the specific needs of individual learners. For example, programs are tailored to learners' needs for specific content media, and applications of technology. Programs also address individual learning styles and preferences, background experience, and knowledge, while providing appropriate assessment and feedback. Appreciation of these needs guides the development and delivery of learning activities that meet consumers' learning objectives.

- Consider what Motivates Learners - DDLM-based programs take into account what attracts and retains learners' attention and are structured to present relevant content that arouses learners perceptually. This involves aesthetically pleasing presentation and technology that is innovative and interactive. Learners also want to be intellectually aroused; to see the relevance and value of what is being learned; to feel confident about being able to complete a learning task; and to be challenged to find solutions. This: involves presenting alternative and contradictory perspectives to inspire comprehension application, analysis, synthesis, and evaluation of knowledge.

- Establish a Collaborative, Healthy Learning Environment-The DDLM emphasizes the role of collaborative learning environments where knowledge evolves through social negotiation. In DDLM-based learning programs, the Web site serves as an electronic performance support system, providing tools, resources, and support systems designed to fit the specific learning environment. Depending on what is needed in the environment, the site might contain a database of resources and information, a coaching and guiding system providing assistance with certain tasks, job aids, and administrative tool such as project management software. Principles of netiquette are explained, understood, and enforced with all users of the learning environment.

- Base Curriculum Design on Program Goals —-The curriculum of DDLM-based programs, is developed by examining program goals, and breaking the goals down into relevant subject areas that determine course content. Industry task analyses are conducted to identify observable outcomes and to inform project course and project design. Once content has been determined, careful planning ensures the maintenance of consistent 
structure throughout the program, a logical progression through material, appropriate and clear presentation, and easy updating and expanding of materials.

- Use Pedagogical Strategies Appropriate for Online Learning - In online learning, the facilitator enables the comprehension of information and encourages self-directed learning. This allows the instructor to capitalize on feedback, engage learners in problem-solving experiences, and to provide positive reinforcement. The facilitator structures experiences that enhance generalization, and creates opportunities to apply the material learned. In addition, program and learner expectations are clear. Any necessary preprogram information (e.g., technical

requirements) is provided to the learner. Learning is embedded in realistic and relevant contexts and social experience.

- Conduct Regular Evaluations of Learners - The evaluation of learners includes a variety of assessment strategies designed to evaluate learners from different perspectives and to allow for different learning styles. The evaluation process is a formative part of the learning process, motivating learners to read, study, and complete assignments. The evaluation process identifies where work products fall short of program criteria and helps learners plan the steps required to further their own learning. Traditional forms of assessment that focus only on recall of knowledge, or have limited response formats might require adaptation to measure the goals and performances of E-learning appropriately.

- Ensure the Program is Convenient for Learners - Many aspects of E-learning programs are implicitly designed to be convenient for learners. In high-quality E-learning systems services such as online administrative services, online bookstores, and online bulletin boards for announcements are offered. Second, continuous access to the program's Web site and related resources is provided. Third, travel requirements are minimal. The learner can complete the program from any location and at any time. This flexibility allows learners to apply the skills they are acquiring as they learn.

\subsubsection{Learner Outcomes}

High-quality E-learning systems provide outcomes such as lower costs for learner (i.e. employee) and employer and other personal advantages for the learner, while achieving learning objectives.

- Lower Costs for Learner and Employer - The financial costs of E-learning systems must be competitive with those of traditional educational programs. Travel expenses are usually eliminated or minimized. Most critical is that learners do not need to take time off work and so can maintain both their salary and their position in the workplace. Employers also benefit, since the corporation does not suffer employee absences. Moreover, both learner and employer may benefit from improved morale resulting from the organizational investment in the learner's development.

- Personal Advantages for the Learner-Learners do not experience the personal stressors associated with financial risk, leaving a job, moving away from family to attend university, or moving their family to further their education.

- Learning Outcomes_-Web-based programs based on the DDLM meet the demands of both employees and employers by providing a program in which learners:

- $\quad$ are satisfied with the learning experience,

- acquire new and relevant skills and knowledge,

- apply the new knowledge and skills in their workplace, and

- $\quad$ add value to their employer.

\subsection{DDLM Dynamic Structure}

Five distinguishing features make the DDLM an appropriate quality standard for E-learning and

Distance Education specially the blended system:

1. Designed to address the needs of adult learners and educators trying to manage new learning technologies.

2. Created to support and guide e-learning designers, instructors, and evaluators towards appropriate workforce learning contexts. 
3. Developed through an iterative and collaborative planning process between academics and industry experts.

4. Includes an "outcomes" component for more effective evaluation of the program.

5. Provides a companion online evaluation survey unique to E-Learning models.

It appears that the DDLM can provide an appropriate framework upon which to base and evaluate ELearning and Distance Education platforms.

The DDLM was developed to answer the need for a quality standard for E-Learning and Distance Education and address the challenges presented by technology and the concerns of the learner and educators relating to technology. The DDLM is a framework for E-Learning and Distance Education that was designed with the needs of working adult learners in mind. It was based on the premise that learners are demanding superior quality content, delivery, and service in education programs in an evolving technological environment. The DDLM was developed by academics with strong foundations in psycho-pedagogy, curriculum design, and evaluation methods and industry experts in both the private and public sector. The collaborative effort thereby ensured pedagogical soundness in the model as well as relevance for the learners, secondary beneficiaries (employers), and educators (including those who design, develop, and deliver the program).

\subsection{Impacts of DDLM on E-Learning and Distance Education Systems:}

A considerable amount of research has been conducted on e-Learning and distance education. The following section highlights several important impacts of DDLM on E-Learning (Carswell, 1997):

\section{Time and location flexibility:}

E-Learning eliminates the barriers of time and distance by offering "just-in-time, on-the-job" learning, and has potential to reach a global audience, including disabled, part-time, and non-traditional people.

\section{Cost and time savings:}

As much as $40 \%$ of money spent on in-person corporate learning is eaten up by travel cost. Since eLearners do not have to travel to a specific location, e-Learning can result in significant cost savings on indirect expenses. It is reported that companies using online training can expect an average of $50 \%$ in time savings and $40 \%$ to $60 \%$ in cost savings, compared with conventional face-to-face training. For example, Hewlett Packard saved $\$ 150,000$ in outside testing costs alone through online learning (Khirallah, 2000).

\section{Self-paced and just-for-me learning:}

E-Learning fosters self-directed and self-paced learning by structuring learner-centric activities. Each learner can select learning activities that best fit his or her own background, interest, and career at that moment, rather than being a passive receptor of information. Researchers have reported that e-Learning can be as effective as traditional instruction methods and leads to more active participation of learners (Beam and Cameron, 1998).

\section{Collaborative learning environment:}

E-Learning links physically separated learners and experts together to form an online collaborative learning community. By electronic means, an e-Learning system encourages learners to ask questions that they may not be able to ask in conventional classrooms, to elicit their personal opinions without inhibition, and to share different ideas with each other more easily through online forums.

\section{Better access to the instructors:}

In an e-Learning environment, learners obtain online guidance and help from instructors. They usually perceive greater opportunities for communication than those in a traditional classroom.

\section{Unlimited use of learning materials:}

E-Learning allows unlimited access and retrieval of electronic learning materials. Information and knowledge are available to learners 24 hours a day. People can review current or past information/knowledge stored in online knowledge repositories over and over again. An e-Learning 
One of the most crucial prerequisites for successful implementation of DDLM in e-learning and distance education is the need for careful consideration of the underlying pedagogy, or how learning takes place online. Effective e-learning includes the integration of instructional practices and Internet capabilities to direct a learner toward a specified level of proficiency in a specified competency".

\section{5 The Regional IT Institute, RITI: The Case under Study}

The Regional IT Institute (RITI) is a not for profit institute that was established in Cairo in 1992 as a subsidiary of the Regional Information Technology and Software Engineering Center (RITSEC) www.ritsec.org.eg. RITSEC was established in 1992, as a joint project between the United Nations Development Program (UNDP) and the Arab Fund for Social \& Economic Development (AFSED); and is hosted by the government of Egypt through the Information and Decision Support Center (IDSC). RITI designs and delivers academic and training development programs in related aspects to information technology, business, management and software development.

Regional IT Institute's mission is to promote a highly qualified and developed generation in the Region through education, training, knowledge creation and dissemination in the fields of business, management, information and communication technologies. RITI is building on a Tradition of Excellence and Meeting the Challenges of the Future to contribute to the business $\&$ socio-economic growth in the region. Our challenge is to maintain our position as one of the main organizations in the creation of knowledge and advanced learning.

Regional IT Institute's scope of activities include; Post Graduate Academic Degree Programs, Training Development Programs, Research and Consultancy. In addition to the organization of Conferences and Exhibitions that targets emerging information, communication and computing technologies.

\subsection{Master of Science in Business IT in Brief}

Recognizing the vital role information and communication technology play in the global business environment. Middlesex University is offering a Master of Science in Business Information Technology in Cairo, Egypt in coordination with the Regional IT Institute. The Programme is franchised to the Institution by Middlesex University. This means that if a student successfully completes all parts of the Programme, he will receive the Middlesex University qualification of Master of Business Information Technology and may if he wishes attend the appropriate Middlesex University graduation ceremony. He will enroll at the Institution as a student of Middlesex University.

The MSc Business Information Technology is a well-established Programme, which has been running for more than 10 years. However, its content has constantly been reviewed and updated to keep up with the ever-changing nature of information technology in business.

Business Information technology is aimed at managers, prospective managers and those who want to understand information technology and be capable of planning, designing and managing information systems within organizations. It provides in-depth knowledge of the competitive use of IT in modern organizations and covers contemporary topics like Internet Commerce and Object-Oriented Development in Java - as well as essential topics such as systems analysis and strategic IT management.

The programme focuses on methods for improving existing information system within organizations and the processes involved in moving to new or revised computer-bases information systems. Students also 
acquire a perspective on database management system structure and function, together with a framework for describing the operation of computer networks. Server programming skills will be studied, which will allow students to create on-line businesses besides programming skills, this will cover issues of security and internet marketing to provide a background to very new and exciting area of computing science.

\section{Aims of MSc. In BIT Programme}

This programme aims to instill an understanding of principles that are imported from different disciplines (Cognitive Psychology, Organizational Theory, Discrete Mathematics and Systems Theory) to underpin the development of Information Technology and Information Systems in business and social contexts. The programme aims to equip students with the knowledge and skills required to identify, and evaluate those situations where Information Technology can make a valuable contribution to commercial and societal efficiency and effectiveness. Finally the programme aims to further the personal and professional development of individual students.

\section{Overall Structure of the BIT Programme}

The program is following DDLM model (see above). The programme is split into 8 taught compulsory modules (four worth 20 credits and four worth 10 credits) as shown in table 2 , and the final project module (worth 60 credits). The framework of learning is being shown in Appendix A. The University academic year is split into 3 semesters (1, 2 and 0$)$ of 15 weeks each.

- Semester 1 (Autumn Semester) starts in September and ends in December.

- Semester 2 (Spring Semester) starts in January and ends in May.

- Semester 0 (Summer Semester) starts in June and ends in August.

Table 2: Course Structure

\begin{tabular}{|l|c|}
\multicolumn{1}{|c|}{$\begin{array}{c}\text { Modules and credit points } \\
\text { * COMPULSORY }\end{array}$} & $\mathbf{1 0}$ \\
\hline BIS4111 Information Systems Analysis and Design & $\mathbf{1 0}$ \\
\hline BIS4127 Management Support Systems & $\mathbf{2 0}$ \\
\hline BIS4222 Database Systems & $\mathbf{2 0}$ \\
\hline BIS4225 Information Systems Management and Strategy & $\mathbf{2 0}$ \\
\hline BIS4226 Internet Commerce & $\mathbf{2 0}$ \\
\hline CCM4223 Computer Networks: Operation and Applications & $\mathbf{1 0}$ \\
\hline CMT4130 Design and Evaluation of Interactive Systems & $\mathbf{1 0}$ \\
\hline CMT4120 Object-oriented Software Development & $\mathbf{6 0}$ \\
\hline BIS4992 Postgraduate Computing Project (Thesis) & $\mathbf{1 8 0}$ \\
\hline Total & \\
\hline
\end{tabular}

The students study for 6 consecutive semesters, taking 30 credits per semester over the first four semesters. The project module is completed over the next two semesters. (Students study 2 modules (30 credits) in each of the first two semesters during the first year and the first semester during the second year and then undertake the project module during the second semester of the second year and the first semester of the final year).

MSc. In BIT and the Blended Learning (hybrid model) at Regional IT Institute

Blended E-Learning is an approach that incorporates both face to face as well as online learning. It is the most commonly used type of E-Learning nowadays. It is a learning mode that combines the adaptability and 
flexibility of open learning with the support of face-to-face teaching. This hybrid model for learning incorporates a combination of Instructor-led, CD-ROM Based Material and web-based instruction \& learning.

"MSc. In BIT" is taught within the framework of a Global Campus (GC) Project. This Global Campus provides E-Learning at Learning Support Centres (LSCs), where RITI is the only LSC offering the "MSc. In BIT" in Egypt. Beside RITI, the program is running in Cyprus, Singapore, Hong Kong and China at the same

time and students do not have to leave their home country (or the place where he is resident) and go to MDX (in UK) to finish his MSc. In BIT.

Students have the flexibility to study online - from home - from the office; s/he is provided access to MDX first class teaching materials and should attend the Learning Support Centre (LSC) for regular tutorials. Attendance at the LSC is an important element of the programme and ensures that students get the support they need from local tutors, liaising directly with Middlesex University staff.

Blended Learning $=$ Access to online teaching material+ CD-ROM-based materials + Online Discussion Forums + email + Face to face tutorials

Students attend face-to-face tutorials, which are conducted by local tutors at their base campus. Students also receive a course reader, especially written for each module, which contains the main module content; a CD-ROM with an outline of the module, activities and web-links. They also take part in online discussions and have access to email. In Brief we can say that the Global Campus at MDX combines local support and tutors with CD Rombased materials and the Internet to enable students and lecturers to work together across the world.

There is and always will be a need for the physical classroom, face to face discussions which help raise many issues and debates that make the students best understand the subject under study. Online learning should be viewed as an additional way to get information to participants and reduce the need for travel and time away from the job.

\section{The Learning Model for the BIT program}

The Global Campus combines tutor-supported distance learning based at a local centre with content delivered via CD Rom and the World Wide Web. In addition to student - tutor interaction at the support centre, the student will be part of an electronic community, across the world.

\section{The Learning Support Centre}

Most weeks, during the trimester, the student is given support through tutorial sessions at the Learning Support Centre, which is RITI. RITI also maintains a library of reading material relevant to the programme. The electronic support for the programme is focused there allowing the student access from home via email, telephone, and fax. RITI also provide access to Global Campus material on the Internet.

\section{Rom}

Course content, software required for accessing the content and software for completing the course work will be provided on CD Rom for easy and inexpensive access and updating.

\section{Face to Face sessions}

They are sessions where fellow students meet on a weekly basis, at the LSC, with the module tutor to consider and talk about aspects of the module.

Each session is four hours in length. For 20 credit module, LSC arranges for are 10 sessions and for each 10-credit module, LSC arranges for 6 sessions. Students are

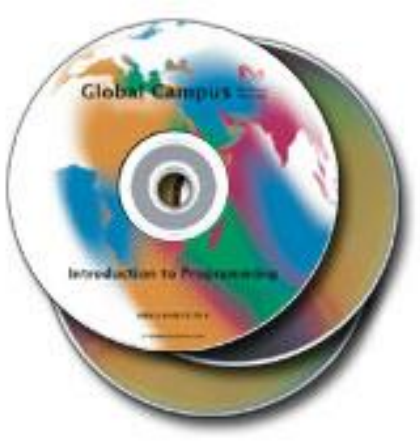
required to attend $75 \%$ of tutorial sessions per module at the LSC. 
In the initial tutorial session for each module the tutor is expected to lead the students through some of the examples given in the learning material and in the textbooks. The tutor goes through some of the worked examples. These are used to reinforce the learning outcomes for each learning unit. They also provide each student with an opportunity to check on his/her own progress as well as using the on-line self-assessment.

As time progresses, the tutorials become more student-led. Students may be at different stages within the module and may find it better to work in groups with the tutor moving between the groups to answer questions and direct study. At all times there is ample opportunity to go through worked examples and receive explanations. At

appropriate junctures, the tutor allocates part of the session's time to explain what is expected from the students on any assessment, course work or examination. Past examination papers and student projects are held in the library at the LSC. Students have the opportunity to email their local tutor at any time or may contact the module leader or any member of either RITI staff or Middlesex staff.

\section{The Virtual Learning Environment (VLE) and the WebCT}

Within the blended learning environment, the E-Learning aspect is strongly represented in the VLE (WebCT).

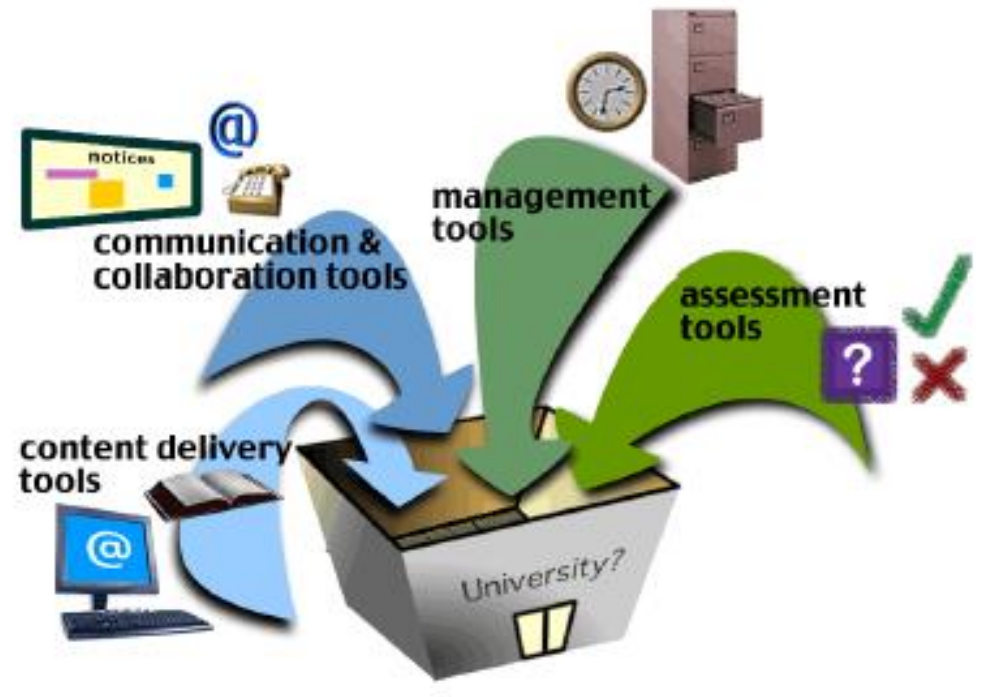

Virtual learning environments (VLEs) consist of:

O Content delivery tools: students can access the study materials

- Assessment tools: with which the module leader can monitor students' progress.

○ Communication and collaboration tools: both synchronous and asynchronous, which the module leader use to communicate and interact with students as well as other tutors

Synchronous Collaboration imitates a classroom, which means collaboration takes place in real-time and connect instructors and students through a chat room. Asynchronous Collaboration allows the student to post his questions on the discussion forum and be provided with answers from the module leader via the same forum.

- Management tools: to help the module leader manage the module, keep track of the students' progress and help him or her manage the resources.

Just as each conventional classroom has its own appearance and character, so each VLE is different. Different classrooms have different tools in which module leader is required to apply a variety of teaching strategies and techniques. The module leader encourages students to join in, meet their peers online, ask questions and contribute to the discussions. 
WebCT is the software being used to deliver Middlesex University's (Virtual learning environment) VLE. It provides a combination of web-based tools assists in the delivery and management of online materials and encourages the building of online communities. WebCT is a place where students can find resources, work through activities and contribute to discussions in support of their studies. To access the WebCT, a student doesn't have to be in a physical institution, at prescribed times or on prescribed days. All their modules have online access to materials and support.

Additional learning resources, particularly interactive resources, are provided via the Worldwide Web. Email and electronic bulletin boards are used extensively by the student for interaction with staff and for peer to peer communication and collaboration.

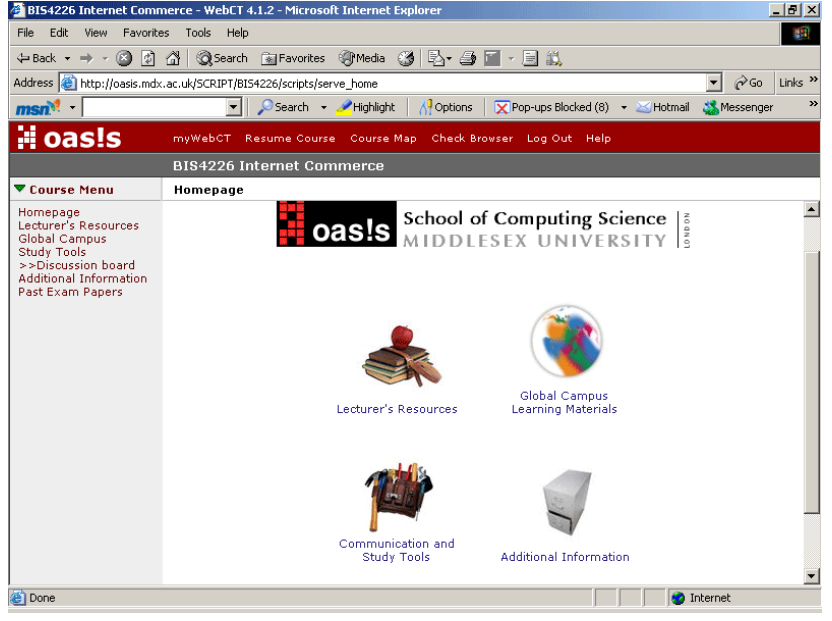


BIS4225 Information Systems Management and Strategy - WebCT 4.1.2 - Microsoft Internet Explorer

File Edit View Favorites Tools Help

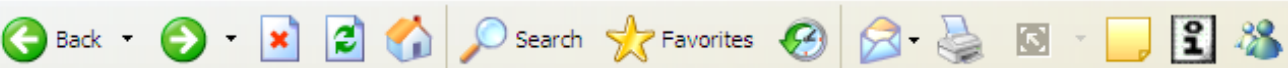

Address http://oasis.mdx.ac.uk/SCRIPT/BIS4225/scripts/serve_home

H Oasls myWebct Resume Course Course Map Check Browser Log Out Help

BIS4225 Information Systems Management and Strategy

$\nabla$ Course Menu

Homepage

Lecturer's Resources

Global Campus

Study Tools

$>>$ Discussion board

Additional Information

\section{Table of Contents}

1. Unit01 - Introduction to Organisations

2. Unit02 - Introduction to Information System Architectures

3. Unit03 - Components of Information System Architectures

4. Unit04 - Virtualisation and Customisation

5. Unit05 - System Development Process

6. Unit06 - Globalisation

7. Unit07 - Systems Failures

8. Unit08 - Intelligent Agents

9. Unit09-Decision Support Systems

10. Unit10 - Maintenance

11. Unit11 - Project Management

12. Unit12 - IS Strategy Planning Approaches

13. Unit13 - Professional, Legal and Ethical Issues

14. Unit14 - Business Process Re-engineering

15. Unit15 - Security of Information and Information Systems

16. Unit16 - Knowledge Management

17. Unit17 - Systems Selection and Acquisition

18. Unit18 - Enterprise Resource Planning

[5]

Each Module is divided into units which represents small chunks of the material ordered in a logical sequence that helps in building up students' knowledge of the subject under study. Usually a 20 credit module is represented in 20 units and 10 credit module is represented in 10 units but this is not a rule. 


\section{ב CMT4120 Object Oriented Software Development - WebCT 4.1.2 - Microsoft Internet Explorer}

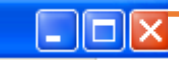

File Edit View Favorites Tools Help

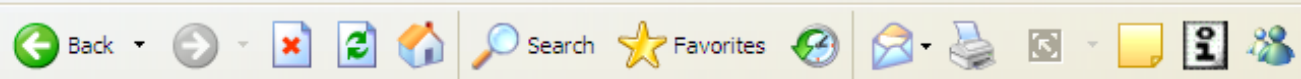

Address http://oasis.mdx.ac.uk/SCRIPT/CMT4120/scripts/serve_home

\section{HH myWebct Resume Course Course Map Check Browser Log Out Help}

CMT4120 Object Oriented Software Development

$\nabla$ Course Menu Homepage > Global Campus Learning Materials > Learning Units > Unit 01 - Introduction

Homepage

Lecturer's Resources

Global Campus

Study Tools

$>>$ Discussion board

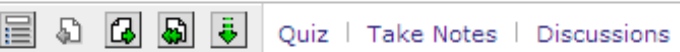

Additional Information

Scope Index

Page: Previous

$1 \quad \vee \quad G 0 \mid$

Next

\section{Scope Index}

Introduction to CMT4021 - Object Concepts and Java

Introduction to the Module

Module Objectives

Prerequisites of the Module

Module Reading Materials and Resources

Coursework and Exams for the Module

e) http://oasis.mdx.ac.uk/SCRIPT/CMT4120/scripts/student/serve_page.pl/CMT4120/global_campus/learnit

Unit 1 of the module usually starts by introducing the module, stating the module's objectives, stating the module's prerequisites, defining the module reading material (core textbooks, supplementary textbooks and online resources) and describing the assessment policy that should be applied (for BIT program $30 \%$ of the grade of each module is based on coursework and $70 \%$ is based on the final exam). 


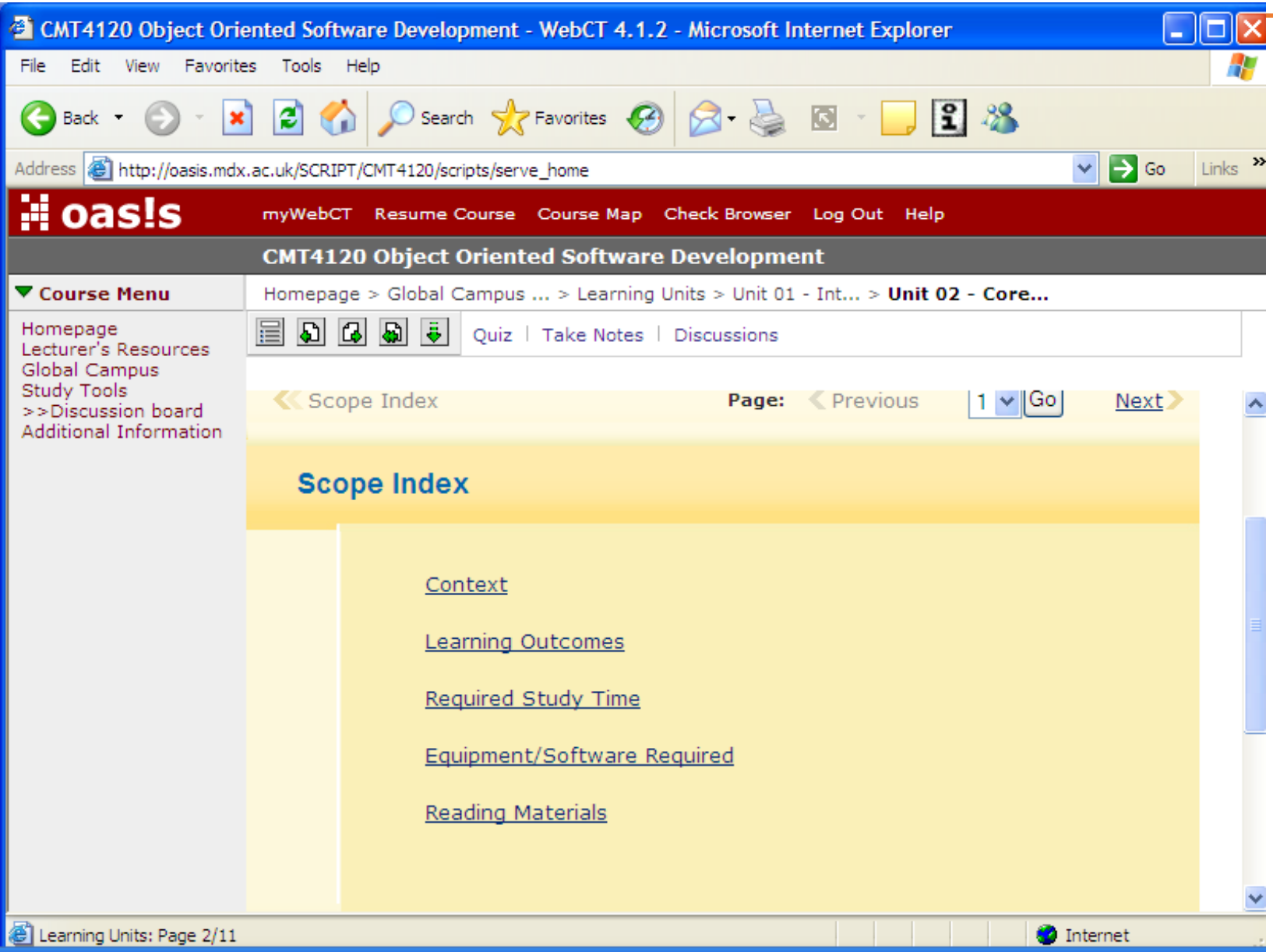

Each unit of the module starts by introducing the unit's purpose, learning outcomes, required study time and equipment/software required.

\section{The Module Leader}

The Module Leader is the designer and monitor of the online course, and thus has a powerful influence on the success or failure of the program. Module Leader's main responsibilities towards their virtual students include:

- Design appropriate curriculum.

- Course planning and organization.

- Construct questions that will have a variety of intellectual levels, varied in their instructional purpose and be open-ended that stimulate thinking and post these questions at the end of each unit with a hint on where students' thinking should be directed.

- Design the whole material for the module and organize course content in units with clear deadlines for the assigned work in each part.

- Set achievable learning outcomes that must offer the opportunity for students to use them in practical, everyday situations.

- Design questions for the assignments and exams.

- Set the agenda and requirements for the whole course in terms of how many hours should each unit take (study time and face to face sessions), what are the activities the students should engage in upon completion of each unit, which software and hardware specifications to be available to best achieve the requirements of each unit, what are the learning outcomes for each unit.

- Design a logical a sequence for the presentation of content and the pace of the material so as to avoid content overload and assure that the course's difficulty is gradually increasing.

- Decide on the deadline for the coursework submission

- Mark the exams 
- Second Mark for a sample of 10 courseworks and has the authority to either approve or disapprove grades assigned to students by the local tutor.

- Post revision slides or docs for students before the exams.

- Conduct from one to three review sessions for the GC students either face to face or via video conference facilities.

- Analyzes students' feedback forms that are filled in electronically to collect information students' perception of the course material's completeness and relevance and efficiency, assignments, local tutor's support and performance, textbooks, learning environment in general, LSC...etc.

\section{The Facilitator (Local Tutor)}

A trained facilitator is an important component of an online program. The facilitator's training, personality, and attitude all impact the online environment. A successful facilitator must know how to integrate life experience, communication, professionalism, and content into the learning environment. The personality of the facilitator is an important component as well, and sets the tone of the classroom. If the facilitator is encouraging and positive, students will quickly develop a level of comfort in the online environment. Facilitators' main responsibilities towards their Virtual Students are:

- Facilitation.

- Conducting face to face sessions

- Marking students' assignments and producing a report with grades to be forwarded with a sample of 10 marked assignments to the module leader for second marking.

- Helping students out with their assignments.

- Conducting presentations as well as facilitates open discussions between the students.

- Acting as a liaison between the module leader fro one side and the students from another side.

- Making sure that the learning outcomes for each unit, were completely and efficiently reached.

- When a facilitator conducts a face to face session, he/she makes sure that it is not a teachercentered classroom in the sense of he/she does not retain the role of "distributor of information" for the whole 4 session hours instead he/she encourages students to get engaged in open discussions and talk about problems they face and ideas they have at their workplace that relate to the module studied. In a teacher-centered classroom, he/she becomes a "guide on the side," helping others to discover and synthesize the learning material.

- Ensuring that consistency and synchronization between what is delivered in class and what is posted on WebCT by the module leader. The facilitator has to stick to the learning outcomes, PPTs, course material, and assignments posted by the module leader on the WebCT.

- Provide leadership and direction without controlling the class. Find a balance between leading the group and creating an environment where students themselves meet the learning objectives. The leadership model becomes one of dynamic facilitation, which is a shift away from an authoritarian style toward a more democratic style.

- Understanding the relationship between the tasks they are required to do and the resources available to them.

- Establishing new study habits and ways of working in a virtual learning environment. Students should be able to:

- manage their time and keep on task

- make the most of the feedback they are given by their peer group and by their tutor(s).

- Supporting students in orientating themselves: keeping track of what they are doing and what needs to be done next. The local tutor should lay bare the structure of their modules and their course as a whole. When modules are structured into small, time-limited, learning units it is often difficult for students to see the bigger picture and what they need to achieve.

- Supporting students in becoming motivated and confident: if they encounter any difficulties (technical or other) they should feel that help is always available. Students should feel that they are studying in a safe and secure environment where they can experiment, make mistakes and learn from them 
- The local tutor should at all times be professional. For the students, he will be the 'public face' of the university. How he deals with them - whether by email or face-to-face - will mould their views of Middlesex University and their programme

Also the LSC is managed by LSC Program Manager and MDX Collaborative Administrators.

\section{Quality Assurance Methods \& Procedures}

According to the DDLM evaluation of the program is being conducted through:

\section{Board of Studies (BoS)}

Student Boards of Study held in weeks 6-8 of each semester allow formal feedback from student representatives regarding their programme of study and associated modules. Academic staff report on their modules at these Boards. Campus Forums deal with the general facilities affecting the student learning experience.

\section{Module Feedback Forms}

Reviews of module delivery via student questionnaires allow feedback of student experience for each module. Questionnaires are analyzed by an automated process, with any issues identified, discussed at Boards of Study, Academic Group meetings and the School Quality Committee.

\section{Reports prepared by Module leaders}

Module leaders provide reports that record general student performance in each written examination on the university's 24-7 student support Web site (at www.mdx.ac.uk/24-7/cs).

\section{Assessment Boards}

Staff provides formal reports at Assessment Boards on the operation of modules/programmes that affect assessment.

\section{External Examiners}

External examiners from other Universities moderate all examination questions before assessment takes place. They also moderate coursework briefs for those modules assessed by more than $50 \%$ coursework. After assessment external examiners review a cross-section of assessed student work and attend and contribute to the Assessment Boards. The external examiners submit formal end-of-year reports to the University's Quality Assurance and Audit Service (QAAS) on their observations, making recommendations as appropriate, and the School formally responds to these and checks that any actions arising from them are completed.

\section{$A M R$}

School and Subject/programme Annual Monitoring Reports (for both MU and Partner provision), are compiled according to QAAS guidelines to consider the effectiveness of subjects and programmes in achieving their stated aims and intended learning outcomes, and the quality of the student experience.

\section{Validation and review events}

Regular Subject and Programme Validation and Review events are carried out by panels of academics from within the School and from outside the School and University to ensure high academic standards are being maintained and enhanced. Student representatives are invited to such events to enable student views to be given directly to the panels.

\section{BCS visit}

The professional body for Computing Science is the British Computer Society (BCS). The Society visits every five years to re-evaluate the quality and standards of programmes they accredit

\section{Synchronization across all campuses}

The same examination papers are sat by students at the same time all over the world, thus ensuring an equivalent experience for all students. 
- Quality of teaching is monitored by peer observation, staff appraisals, training and dissemination of good practice

- New ideas to improve teaching methods and learning resources are discussed in regular meetings of teaching staff in academic groups.

- Student progression for each module is closely monitored by the School Quality Committee, and reported on by programme and curriculum leaders as part of the annual monitoring process.

\subsection{Master of Science in Human Resource Education in Brief}

Regional IT Institute also in cooperation with university of Louisville in USA is offering another blended model of distance education to provide the Master of Science in human resource education since 2003. The programme is designed to help human resource professionals understand, develop, and implement appropriate tactics and strategies to respond to the changes faced by businesses and industry in Cairo and elsewhere in the global economy. It is a 18 month, 30 credit hour program, culminating in a professional thesis that consists of 10 courses, three out of those are base on on-line learning. Each course is equivalent to 3 credit hours. The framework of learning is being shown in Appendix B.

Table 3: Course Structure

\begin{tabular}{|c|c|}
\hline \multicolumn{2}{|c|}{ Modules and Mode of Delivery } \\
\hline * COMPULSORY & Mode of Delivery \\
\hline ELFH605 Managing Human Resource Developmer & \multirow{4}{*}{$\begin{array}{c}\text { In class (Local Instructor must be a PhD holder), } \\
\text { number of lectures per course }=9 \text { lectures. }\end{array}$} \\
\hline ELFH611 Performance Improvement. & \\
\hline ELFH699 Thesis Preparation. & \\
\hline ELFH600 Research Methods \& Statistics. & \\
\hline ELFH662 Organizational Analysis. & \multirow{3}{*}{$\begin{array}{c}\text { In class (Foreign Instructor must be a PhD } \\
\text { holder), number of lectures per course }=9 \text { lectures. }\end{array}$} \\
\hline ELFH672 Training Intervention Design. & \\
\hline ELFH664 Managing Change. & \\
\hline ELFH661 Adult Learning \& Human Resources. & \multirow{3}{*}{$\begin{array}{c}\text { Via Internet (UofL Backboard) + } 3 \text { supporting } \\
\text { sessions per course are delivered by an HR } \\
\text { Practitioner or an HR expert (who has } \\
\text { accumulated a large experience working in the } \\
\text { field of HR). }\end{array}$} \\
\hline ELFH663 Training Strategies in Human Resources. & \\
\hline ELFH614 Program Planning \& Evaluation. & \\
\hline
\end{tabular}

\section{Conducting the research and the Findings}

4 focus groups have been conducted with participants in the two postgraduate programs, the BIT with Middlesex University as well as the Human resource program with university of Louisville. The research was done according to the DDLM model discussed before. Participants have been asked to give their opinion and feedback on their definitions of E-learning and distance education, their expectations for both the traditional versus the blended one. The participants have also asked to give their practices concerning the content, delivery and services of the current program. As for the quality and outcomes, the participants have been requested to give their feedbacks. 


\subsection{Findings and Discussion}

In the figures below we can deduct that the there was no significant difference in the content, when the participants expressed their feedbacks. However, significant difference can be noticed in the Delivery as well as service between the expected and the actual dimensions of the DDLM model especially for the favor of the actual performance of the Hybrid learning model.

As for the quality and the outcomes dimensions, it was very obvious that the perceptions of the participants were indicating that the hybrid model of learning has exceeded their expectations.

When the participants have been asked about their overall view about the current model, they all agreed that, the experiences is very worthwhile trying and continuing it, but with some suggestions to improve the model, as this model is very important to the Egyptian society.

- Stressing on increasing the interactivity between tutor and students and students themselves

- Improve the communications between the facilitator (tutor) and the module leader

- Increase number of Video Conferencing sessions to be able to break the ice between the students and the module leader

- Material should be more up-to-date

- The need for marketing activities to the model

- The need for accreditations from the Supreme Council of Egyptian Universities

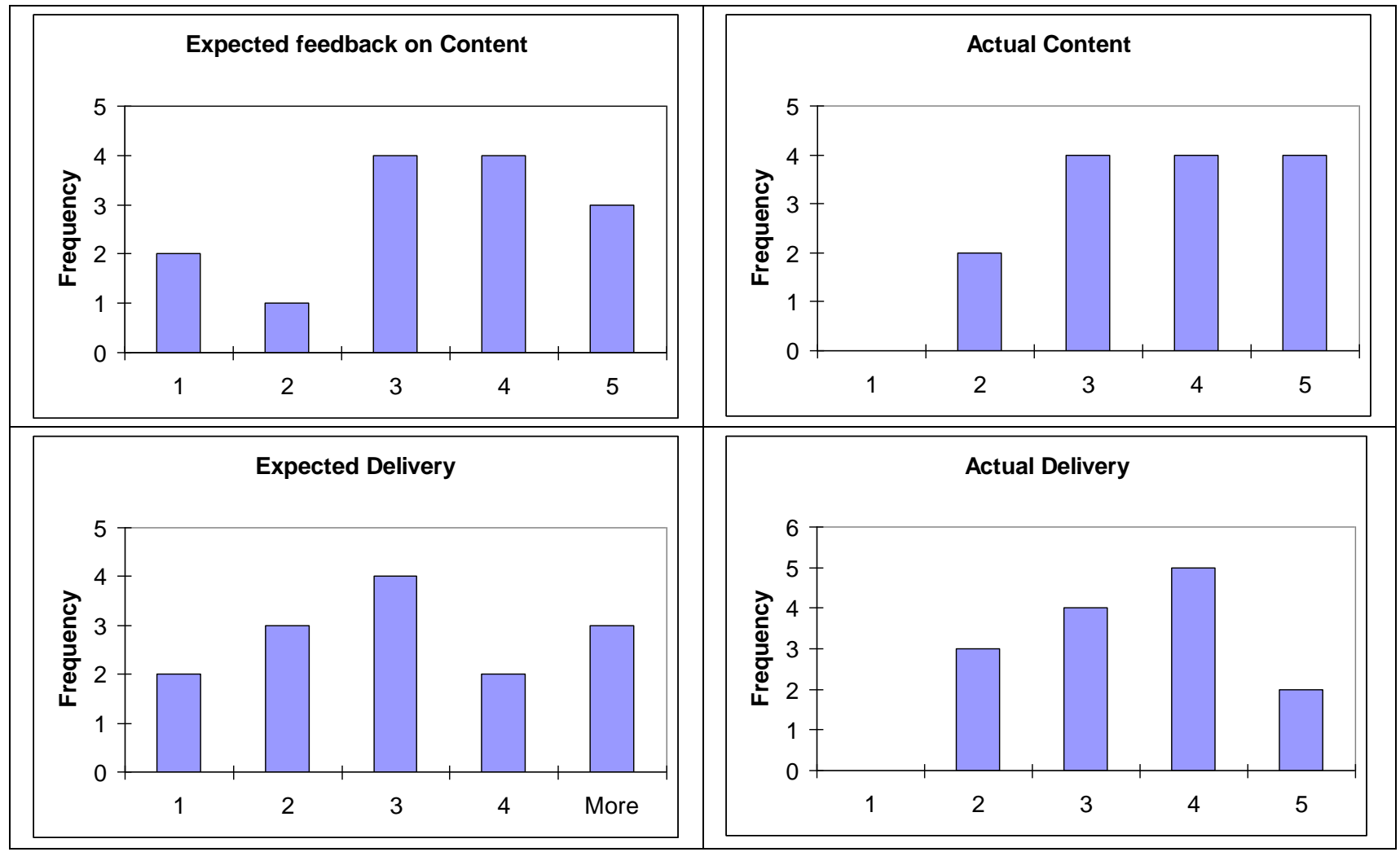




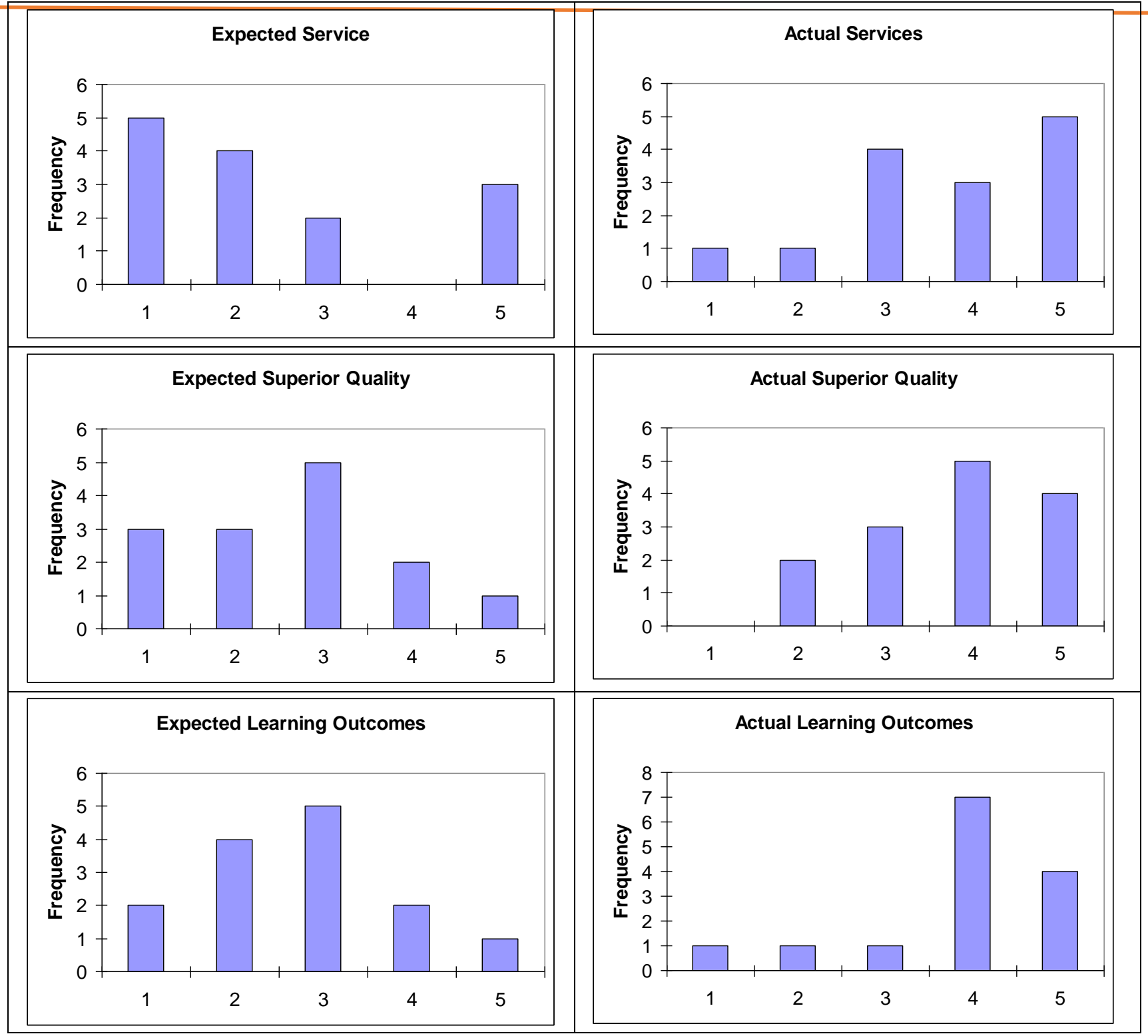

\section{Conclusion}

In this study the case of best practice of the Regional IT Institute has been demonstrated in its experiences in offering the blended distance education through providing the postgraduate Master of Science in business information technology jointly with Middlesex University, UK and the Master of Science in human resource education jointly with University of Louisville, USA. The research has been conducted by using the DemandDriven Learning Model to measure the extent of perceptions from the participants' side with respects to the model dimensions; Content, Delivery, Services, Quality and learning outcomes. The results showed that the Hybrid learning model has showed success with some reservations from the side of the participants to improve the model as they have shown that they are convinced with the blended model of learning. 


\section{References}

http://www.ymlp.com/pubarchive_show_message.php?eLearning+296

http://www.bsu.edu/classes/nasseh/study/history.html

http://www.ymlp.com/pubarchive show message.php?eLearning+296

http://www.knowledgenet.com/corporateinformation/ourhistory/history.jsp

http://www.ymlp.com/pubarchive show message.php?eLearning+296

http://www.westvalley.edu/wvc/trc/seven.html

http://www.elearnspace.org/Articles/Week1 Elearningvs.Classrooms.htm

http://www.internettime.com/Learning/articles/OTH.doc

http://www.e-learningguru.com/wpapers/eLearning ASP.doc

http://www.oxford-elearning.com/demo/elearningcourse/

http://hosting.guidetools.co.nz/scripts/runisa.dll?GUIDE:GT::mthd=PAGE\&course=GUIDEELEARNIN GENGINEWEBSITEMAY03\&pageid=TRAINERSINTRO1\&template $=$ tplWebSiteuide1.htm

http://www.learningcircuits.org/2002/oct2002/taylor.html

McAllister NC, McAllister DF. Providing education electronically to non-traditional sites: New delivery to a new audience. In: Proceedings of the 14th Annual Int'l Conference on Marshaling New Technological Forces: Building a Corporate, Academic, and User-Oriented Triangle, 187-193, 1996.

Marold KA, Larsen G, Moreno A. Web-based learning: Is it working? A comparison of student performance and achievement in Web-based courses and their in-classroom counterparts. Challenges of Information Technology Management in the 21st Century,:350-353. Available: Idea group publishing, 2000.

Dr Micehelle Haynes, Kyriaki Anagnostopoulou, Professor Barry Jackson \& Walaa Bakry. eLearning, A study guide. Middlesex University. 2004.

Barron T., LoD Survey: Quality and Effectiveness of E-Learning, http://www.learningcircuits.org, May 16, 2003.

Baume, D. Monitoring and Evaluating Staff and Educational Development, forthcoming chapter in A Guide to Staff and Educational Development, SEDA publication, 2004.

Beam P, Cameron B. Evaluating online learning as a process. In: Proceedings on the Sixteenth Annual International Conference on Computer Documentation, Sept. 24-26, 1998.

Breithaupt K. \& MacDonald C. J., Quality Standards for E-Learning: Cross Validation Study of the Demand Driven Learning Model (DDLM), TESTING INTERNATIONAL, Vol. 13, No. 1, 2003.

Carr, C.S., \& Carr, A.M. Instructional design in distance education (IDDE): A web-based performance support system for educators and designers. The Quarterly Review of Distance Education, 1 (4), 317-325.,2000

Carswell L. Teaching via the Internet: The impact of the Internet as a communication medium on distance learning introductory computing students. In: Proceedings of the Conference on Integrating Technology into Computer Science Education, June 1-5, 1997.

Kerrey B, Isakson J. The power of the Internet for learning: Moving from promise to practice. Report of the Web-Based Education Commission to the President and the Congress of the United States. Available:

http://www.ed.gov/offices/AC/WBEC/FinalReport/WBECReport.pdf, 2000. 
Khirallah DR. A new way to learn. Information week 22-23. Available: http://www.informationweek.com, 2000.

Kyriakos V., Anastasios A., Nikoleta E., "Evaluation of web based educational systems", Journal of Business Education, VOL. 1 PROCEEDINGS, 2000.

Marold KA, Larsen G, Moreno A. Web-based learning: Is it working? A comparison of student performance and achievement in Web-based courses and their in-classroom counterparts. Challenges of Information Technology Management in the 21st Century,:350-353. Available: Idea group publishing, 2000.

McAllister NC, McAllister DF. Providing education electronically to non-traditional sites: New delivery to a new audience. In: Proceedings of the 14th Annual Int'l Conference on Marshaling New Technological Forces: Building a Corporate, Academic, and UserOriented Triangle, 187-193, 1996.

MacDonald, C J, Stodel, E J, Farres, L G, Breithaupt, K, Gabriel, M A 2001. The demand-driven learning model DDLM: a framework for web-based learning. The Internet and Higher Education 4:9-30, 2001.

MacDonald, C. J., Breithaupt, K., Stodel, E. J., Farres, L. G., \& Gabriel, M. A.. Evaluation of web-based educational programs: A pilot study of the Demand-Driven Learning Model DDLM. International Journal of Testing, 2(1), 35-61., 2002. 


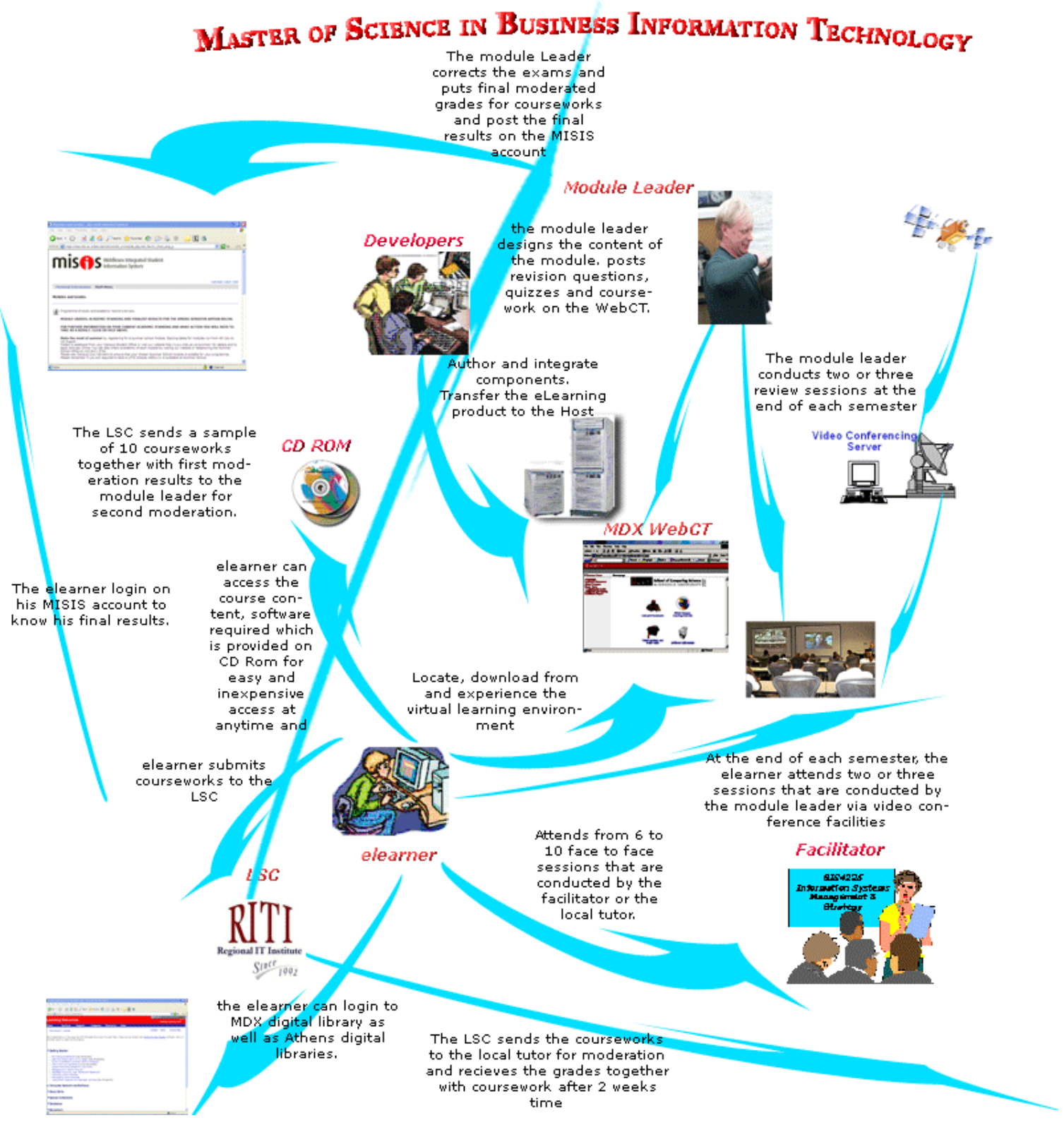




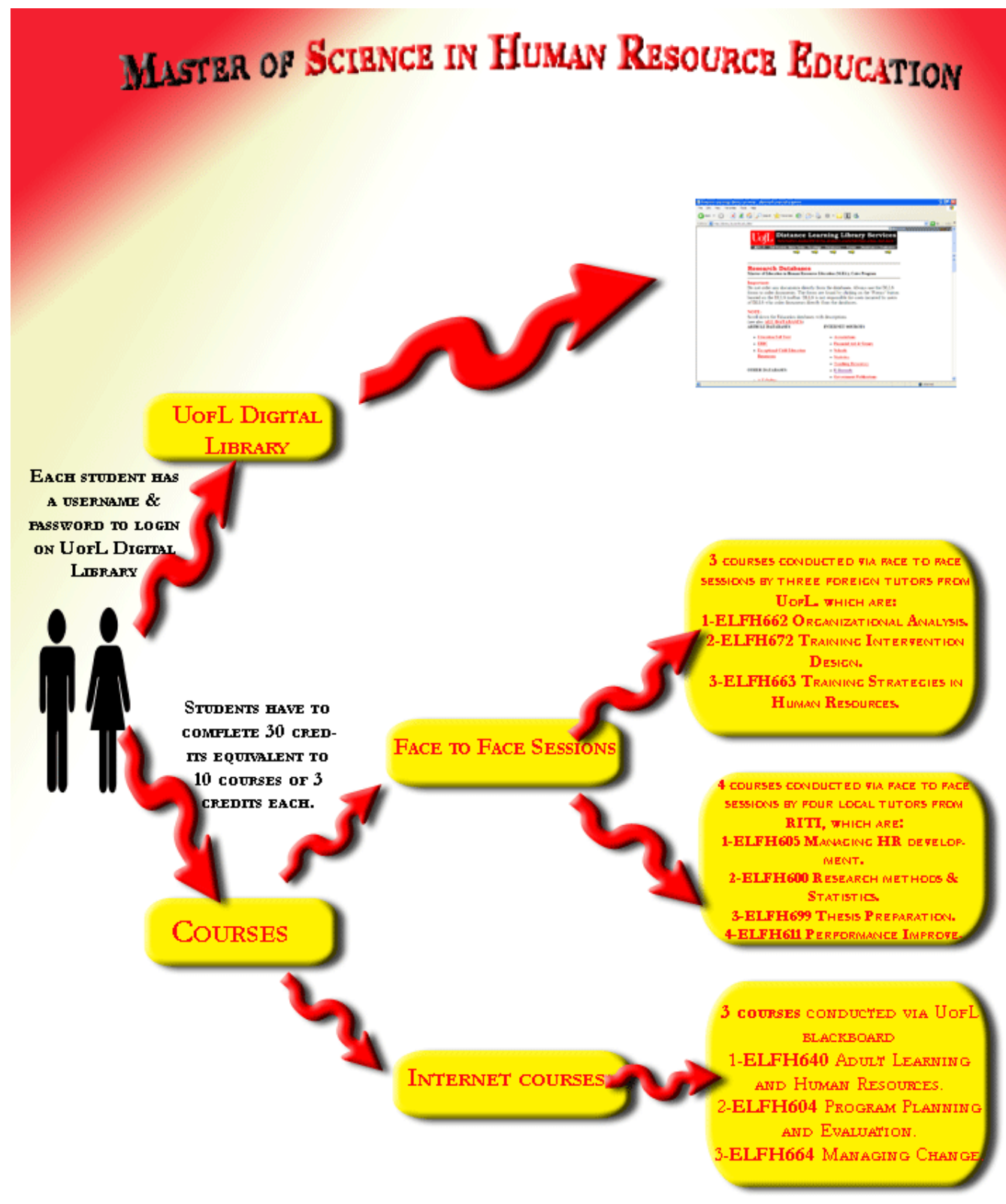

